\title{
Analysis of renal lesions in Chinese tuberous sclerosis complex patients with different conditions of TSC1/2 genetic mutations
}

\section{Wenda Wang}

Peking Union Medical College Hospital

\section{Yang Zhao}

Peking Union Medical College Hospital

\section{Xu Wang}

Peking Union Medical College Hospital

\section{Zhan Wang}

Peking Union Medical College Hospital

\section{Guoyang Zheng}

Peking Union Medical College Hospital

\section{Yi Cai}

Xiangya Hospital Central South University

\section{Hua Fan}

Peking Union Medical College Hospital

\section{Hanzhong Li}

Peking Union Medical College Hospital

Yushi Zhang ( $\sim 15120002969 @ 163 . c o m$ )

Peking Union Medical College Hospital

\section{Research}

Keywords: tuberous sclerosis complex (TSC), genetic mutations, renal lesions, no mutation identified (NMI), familial

Posted Date: March 4th, 2020

DOI: https://doi.org/10.21203/rs.3.rs-15210/v1

License: (c) (i) This work is licensed under a Creative Commons Attribution 4.0 International License. Read Full License 


\section{Abstract}

Objective The renal manifestations of tuberous sclerosis complex (TSC) are complicated and various. We'd like to report the information of genetic mutations in TSC patients with renal lesions, and to discuss the relationship between features of renal lesions and genetic mutations, including mutant genes and mutant types. Methods TSC patients with renal lesions who came to Urology Department of our hospital from January 1st, 2015 to January 1st, 2020 were retrospectively analyzed. TSC patients who received next generation sequencing (NGS) of TSC1/2 and imaging examinations were screened out. When familial TSC patients were confirmed, only the probands were included. The patients who had imaging evaluation in our hospital before any treatment for TSC renal angiomyolipomas (AMLs) were also selected for further analysis of relationship between genetic mutations and AML sizes. Results 70 clinically or genetically diagnosed TSC patients with renal lesions were included. The average age was $29.3 \pm 8.3$ years old. Male-female ratio was $1: 1.5$. 15 patients $(21.4 \%)$ were probands of TSC families (3 TSC1 , 10 TSC2, and 2 NMI). 67 patients (95.8\%) had bilateral renal AMLs with one patient had a pathological diagnosis of epithelioid AML ( TSC2 mutation). One patient had multiple renal cysts ( TSC2 mutation), one had renal cell carcinomas (RCCs) ( TSC1 mutation) and one had Wilms tumors ( TSC1 mutation). Among the 70 included patients, 4 patients had TSC1 mutations, 51 had TSC2 mutations, and 15 had no mutation identified (NMI). There was no statistically significant difference between TSC2 mutations and NMI groups $(11.4 \pm 5.7$ vs. $8.0 \pm 5.6 \mathrm{~cm}, P=0.077)$ when considering $A M L$ sizes. There was also no statistically significant difference among AML sizes of patients with TSC2 mutation types of nonsense, missense, frameshift, slipping, and fragment deletion $(P=0.712)$. And no statistically significant difference was found between maximus diameters in familial and sporadic patients, either (11.4 \pm 5.8 vs. 10.5 $\pm 5.8, P=0.663)$. Conclusions The conditions of TSC genetic mutations will affect type and severity of renal lesions. Other focuses such as protein structure and function need to be studied for renal manifestations. Except for patients with TSC1 and TSC2 genetic mutations, patients with NMI and familial patients are also needed more attention for the pathogenesis of them is still unknown.

\section{Introduction}

Tuberous sclerosis complex (TSC) is an autosomal dominant genetic disorder characterized by hamartomas in organs including the brain, kidney, lung, skin, and heart ${ }^{[1]}$. The birth incidence of TSC has been estimated to be approximately 1 in $6000^{[2]}$. Renal lesions are the most common cause of death in adult TSC patients. These renal diseases of TSC may occur in early childhood with progress throughout adulthood ${ }^{[3]}$. The most common kidney manifestation of TSC is angiomyolipoma (AML), which occurs in 70-90\% TSC patients ${ }^{[4]}$. The other kinds of lesions include renal cysts and renal cell carcinomas (RCCs).

75-90\% of patients who meet TSC standard clinical criteria present TSC1 or TSC2 mutations ${ }^{[5]}$, and about 60$70 \%$ of TSC cases are sporadic ${ }^{[6-7]} .10-15 \%$ of patients have no TSC1 or TSC2 mutations (also known as no mutation identified, NMI), although these patients could be clinically diagnosed. In the previous studies, researchers found that patients with TSC2 mutations present severer clinical features than others ${ }^{[8-11]}$. However, the studies focus on the relationship between TSC genetic mutations and TSC renal lesions are relatively few. Here we report the information of genetic mutations in TSC patients with renal lesions, and discuss the relationship between renal lesions and TSC mutations, including mutant genes and mutant types.

\section{Methods}




\section{Participants}

We retrospectively analyzed TSC patients with renal lesions who came to Urology Department of Peking Union Medical College Hospital (PUMCH) from January 1st, 2015 to January 1st, 2020. The diagnosis of TSC was made based on the clinical diagnostic criteria of the 2012 international tuberous sclerosis complex consensus conference ${ }^{[4]}$ or genetic diagnosis of TSC1/2 gene. TSC patients who received next generation sequencing (NGS) of TSC1/2 genes and imaging examinations were screened out for analysis of genetic and clinical features. When familial TSC patients were confirmed, only the probands were analyzed. The patients who had imaging evaluation in our hospital before any treatment for TSC renal AMLs were also selected for further analysis of relation between genetic mutations and AML sizes. We recorded the maximum diameter at the biggest cross-section of the largest lesion in each patient. Our study was approved by the Ethics Committee of PUMCH. Written informed consent was obtained from all the subjects for genetic tests and clinical information analysis.

\section{NGS and mutation analysis}

Genomic DNA was extracted from peripheral blood leukocytes using QIAamp DNA Blood Mini Kit (Qiagen, Hilden, Germany). The genomic DNA was fragmented into $200 \sim 250$ bp fragments and was purified by Agencourt AMPure XP kit (BGI-Shenzhen, Shenzhen, China). After modification of DNA fragments, ligation-mediated polymerase chain reaction (PCR) and purification were conducted, following the hybridization reaction using the customized gene fragment-capturing chips (Roche NimbleGen, Madison, WI). Amplification with the highfidelity DNA polymerase and high-throughput sequencing of the qualified DNA samples were carried out for continuous bidirectional sequencing of 90 cycles. The Illumina basecalling software (V. 1.7, Illumina) was used to deal with the original image data, and the Burrows-Wheeler Aligner software (BGI-Shenzhen, Shenzhen, China) was used for sequence alignments of qualified raw reads, which had been conducted using sequencing quality assessment. The bam data were used for reads coverage in the target region and sequencing depth computation, single-nucleotide polymorphism (SNP) and insertion-deletion calling, and copy number variation detection. First, SNPs and insertiondeletions were called using SOAPsnp software (BGI-Shenzhen, Shenzhen, China) and Samtools pileup software (BGI-Shenzhen, Shenzhen, China), respectively. Second, if an SNP frequency was more than 0.05 in any of the 4 databases (dbSNP, HapMap, 1000 Genomes Project, and BGI local database), it would be regarded as a polymorphism, not a causative mutation. Lastly, all of the mutations were retrieved from the Leiden Open Variation Database (LOVD) databases to be labeled as already reported or novel.

The sequences of the Homo sapiens hamartin and tuberin proteins were obtained from the National Center for Biotechnology Information database. The mutations in the TSC1 or TSC2 gene were compared with those in the Tuberous Sclerosis Database. The possible impact of the identified mutations on protein function, as a result of an amino acid substitution, was examined using available online tools SIFT and PolyPhen-2.

After probable causative mutations were found, participants and their affected family members underwent Sanger sequencing or quantitative PCR to verify the mutations. The PCR cycling protocol consisted of an initial denaturation at $95{ }^{\circ} \mathrm{C}$ for 3 minutes, followed by 35 cycles, at $95^{\circ} \mathrm{C}$ for 40 seconds, at $55^{\circ} \mathrm{C}$ for 30 seconds, and at $72{ }^{\circ} \mathrm{C}$ for 30 seconds, with a final extension at $72{ }^{\circ} \mathrm{C}$ for 10 minutes.

\section{Statistical analysis}

All statistical analyses were performed using SPSS19.0 software (SPSS Inc., USA). Data were expressed as means \pm standard deviation (mean \pm SD) or $\mathrm{n}(\%)$ as appropriate. Student's unpaired $\mathrm{t}$ test or Tukey test was used to 
determine differentiation state of continuous variables between different groups. A P value of less than 0.05 was considered statistically significant.

\section{Results}

In total, 70 clinically or genetically diagnosed TSC patients with renal lesions were retrospectively analyzed during January 1st, 2015 to January 1st, 2020 in PUMCH. The average age was $29.3 \pm 8.3$ years old. There were more female patients with a male-female ratio of $1: 1.5$. 15 patients $(21.4 \%)$ were probands of TSC families (3 TSC1, 10 TSC2, and $2 \mathrm{NMI}$ ). When all the familial TSC patients were included, there were 95 patients in total. Among the 70 patients for analysis, 67 patients $(95.8 \%)$ had bilateral renal AMLs with one patient had a pathological diagnosis of epithelioid AML. The patient received surgical resection for rapid progress. The renal lesions were multiple renal cysts in one patient, RCCs in one patient and Wilms tumors in one patient, respectively (Table 1).

Table 1

Demographic characteristics of 70 patients.

\begin{tabular}{|ll|}
\hline Age (yr, M \pm SD) (range) & $29.3 \pm 8.3(8 \sim 45)$ \\
\hline Gender & $28 / 70(40.0 \%)$ \\
\hline Male & $42 / 70(60.0 \%)$ \\
\hline Female & $15 / 70(21.4 \%)$ \\
\hline Familial TSC & \\
\hline Renal lesions & $67 / 70(95.8 \%)$ \\
\hline AML & $1 / 70(1.4 \%)$ \\
\hline Epithelioid AML & $1 / 70(1.4 \%)$ \\
\hline Multiple renal cysts & $1 / 70(1.4 \%)$ \\
\hline Renal cell carcinomas & $1 / 70(1.4 \%)$ \\
\hline Wilms tumor & \\
\hline
\end{tabular}

Among the 70 TSC patients, 4 patients had TSC1 gene mutation. The patient with RCCs had nonsense mutation of TSC1 gene at c.2227C > T. The patient with Wilms tumors had fragment deletion of TSC1. 51 patients had TSC2 gene mutation. One patient with fragment deletion of TSC2 had the renal lesions of multiple renal cysts. No TSC1 or TSC2 gene mutation were detected in 15 patients with clinical diagnosis (Table 2). The details were summarized in Tables 3 and 4. 
Table 2

TSC1 and TSC2 gene mutations in 70

patients.

\begin{tabular}{|ll|}
\hline TSC1 & $4 / 70$ (5.7\%) \\
\hline Nucleotide mutation & \\
\hline Nonsense & $3 / 4(75.0 \%)$ \\
\hline Fragment mutation & $1 / 4(25.0 \%)$ \\
\hline TSC2 & $51 / 70(72.9 \%)$ \\
\hline Nucleotide mutation & \\
\hline Nonsense & $18 / 51(35.3 \%)$ \\
\hline Missense & $7 / 51(13.7 \%)$ \\
\hline Frameshift & $15 / 51(29.4 \%)$ \\
\hline Slipping & $4 / 51(7.9 \%)$ \\
\hline Fragment mutation & $7 / 51(13.7 \%)$ \\
\hline NMI & $15 / 70(21.4 \%)$ \\
\hline
\end{tabular}

Table 3

TSC1 gene mutation data.

\begin{tabular}{|llllll|}
\hline Site & Mutation type & Protein change & Lesions & Familial or not & Pathogenicity \\
\hline Nucleotide mutation & & & & \\
\hline c.733C $>T$ & Nonsense & p.Arg245Ter & AML & Yes & Pathogenic \\
\hline c.2227C $>$ T & Nonsense & p.GIn743Ter & RCC & No & Pathogenic \\
\hline c.1372C $>$ T & Nonsense & p.Arg458Ter & AML & Yes & Pathogenic \\
\hline Fragment mutation & & & & \\
\hline EX9_12DEL & - & - & Nephroblastoma & No & Likely pathogenic \\
\hline
\end{tabular}


Table 4

TSC2 gene mutation data.

\begin{tabular}{|c|c|c|c|c|c|}
\hline Site & $\begin{array}{l}\text { Mutation } \\
\text { type }\end{array}$ & Protein change & Lesions & $\begin{array}{l}\text { Familial } \\
\text { or not }\end{array}$ & Pathogenicity \\
\hline \multicolumn{6}{|c|}{ Nucleotide mutation } \\
\hline c. $3581 G>A$ & Nonsense & p.Trp1194Ter & AML & No & Pathogenic \\
\hline c. $3685 \mathrm{C}>\mathrm{T}$ & Nonsense & p.GIn1229Ter & AML & Yes & Pathogenic \\
\hline c. $2194 \mathrm{C}>\mathrm{T}$ & Nonsense & p.GIn732Ter & AML & No & Pathogenic \\
\hline c. $1874 \mathrm{C}>\mathrm{G}$ & Nonsense & p.Ser625Ter & AML & No & Pathogenic \\
\hline c. $1513 \mathrm{C}>\mathrm{T}$ & Nonsense & p.Arg505Ter & AML & No & Pathogenic \\
\hline c. $658 \mathrm{C}>\mathrm{T}$ & Nonsense & p.GIn220Ter & AML & No & Pathogenic \\
\hline c. $2194 \mathrm{C}>\mathrm{T}$ & Nonsense & p.GIn732Ter & AML & No & Pathogenic \\
\hline c. $2590 \mathrm{C}>\mathrm{T}$ & Nonsense & p.GIn864Ter & AML & No & Pathogenic \\
\hline c. $3685 \mathrm{C}>\mathrm{T}$ & Nonsense & p.GIn1229Ter & AML & No & Pathogenic \\
\hline c. $3412 \mathrm{C}>\mathrm{T}$ & Nonsense & p.Arg1138Ter & AML & No & $\begin{array}{l}\text { Likely } \\
\text { pathogenic }\end{array}$ \\
\hline c. $3412 \mathrm{C}>\mathrm{T}$ & Nonsense & p.Arg1138Ter & AML & No & Pathogenic \\
\hline c. $4129 \mathrm{C}>\mathrm{T}$ & Nonsense & p.GIn1377Ter & AML & No & $\begin{array}{l}\text { Likely } \\
\text { pathogenic }\end{array}$ \\
\hline c. $4129 \mathrm{C}>\mathrm{T}$ & Nonsense & p.GIn1377Ter & AML & No & $\begin{array}{l}\text { Likely } \\
\text { pathogenic }\end{array}$ \\
\hline c. $3412 \mathrm{C}>\mathrm{T}$ & Nonsense & p.Arg1138Ter & AML & No & Pathogenic \\
\hline c. $3750 C>G$ & Nonsense & p.Tyr1250Ter & AML & No & Pathogenic \\
\hline c. $4255 \mathrm{C}>\mathrm{T}$ & Nonsense & p.GIn1419Ter & AML & No & Pathogenic \\
\hline c. $1507 \mathrm{C}>\mathrm{T}$ & Nonsense & p.GIn503Ter & AML & No & $\begin{array}{l}\text { Likely } \\
\text { pathogenic }\end{array}$ \\
\hline c. $1108 \mathrm{C}>\mathrm{T}$ & Nonsense & p.GIn370Ter & AML & No & $\begin{array}{l}\text { Likely } \\
\text { pathogenic }\end{array}$ \\
\hline c. $1831 \mathrm{C}>\mathrm{T}$ & Missense & p.Arg611Trp & AML & No & Pathogenic \\
\hline c. $3475 \mathrm{C}>\mathrm{T}$ & Missense & p.Arg1159Trp & AML & No & VUS \\
\hline c. $5126 \mathrm{C}>\mathrm{T}$ & Missense & p.Pro1709Leu & AML & No & Pathogenic \\
\hline c. $5024 \mathrm{C}>\mathrm{T}$ & Missense & p.Pro1675Leu & AML & No & Pathogenic \\
\hline c. $1831 \mathrm{C}>\mathrm{T}$ & Missense & p.Arg611Trp & AML & No & Pathogenic \\
\hline c. $2032 \mathrm{G}>\mathrm{A}$ & Missense & p.Ala678Thr & AML & No & $\begin{array}{l}\text { Likely } \\
\text { pathogenic }\end{array}$ \\
\hline
\end{tabular}




\begin{tabular}{|c|c|c|c|c|c|}
\hline Site & $\begin{array}{l}\text { Mutation } \\
\text { type }\end{array}$ & Protein change & Lesions & $\begin{array}{l}\text { Familial } \\
\text { or not }\end{array}$ & Pathogenicity \\
\hline c. $856 A>G$ & Missense & p.Met286Val & AML & No & $\begin{array}{l}\text { Likely } \\
\text { pathogenic }\end{array}$ \\
\hline c.2233_2234del & Frameshift & p.Lys745AspfsX16 & AML & Yes & Pathogenic \\
\hline c. $1852 \mathrm{del}$ & Frameshift & p.Leu618CysfsX80 & AML & No & Pathogenic \\
\hline c.1047dup & Frameshift & p.Arg350Ter & AML & Yes & Pathogenic \\
\hline c.4544_4547del & Frameshift & p.Asn1515SerfsX60 & AML & Yes & Pathogenic \\
\hline c.1762_1763del & Frameshift & p.Glu588Terfs & AML & No & $\begin{array}{l}\text { Likely } \\
\text { pathogenic }\end{array}$ \\
\hline c.788_789insC & Frameshift & p.Leu263LeufsX75 & AML & Yes & $\begin{array}{l}\text { Likely } \\
\text { pathogenic }\end{array}$ \\
\hline c.4006_4007insC & Frameshift & p.Ser1336SerfsX78 & AML & No & $\begin{array}{l}\text { Likely } \\
\text { pathogenic }\end{array}$ \\
\hline c.203_204 insA & Frameshift & p.Ala68AlafsX7 & AML & Yes & $\begin{array}{l}\text { Likely } \\
\text { pathogenic }\end{array}$ \\
\hline c.3683_3684insG & Frameshift & p.Leu1228LeufsX6 & AML & No & $\begin{array}{l}\text { Likely } \\
\text { pathogenic }\end{array}$ \\
\hline c.2738_2739 insT & Frameshift & p.Thr913ThrfsX2 & AML & No & $\begin{array}{l}\text { Likely } \\
\text { pathogenic }\end{array}$ \\
\hline c.2319 delA & Frameshift & p.Leu773LeufsX56 & AML & No & $\begin{array}{l}\text { Likely } \\
\text { pathogenic }\end{array}$ \\
\hline c.3601_3602insGGCCC & Frameshift & p.Thr1203GlyfsX9 & AML & No & $\begin{array}{l}\text { Likely } \\
\text { pathogenic }\end{array}$ \\
\hline c.4926delC & Frameshift & p.Asn1643ThrfsX29 & AML & No & $\begin{array}{l}\text { Likely } \\
\text { pathogenic }\end{array}$ \\
\hline c.788_789insC & Frameshift & p.Leu263LeufsX75 & AML & No & $\begin{array}{l}\text { Likely } \\
\text { pathogenic }\end{array}$ \\
\hline c.1201_1202insA & Frameshift & p.His401GInfsX9 & AML & Yes & $\begin{array}{l}\text { Likely } \\
\text { pathogenic }\end{array}$ \\
\hline c. $976-1 G>A$ & Splicing & - & AML & No & Pathogenic \\
\hline c. $1444-1 \mathrm{G}>\mathrm{C}$ & Splicing & - & AML & No & $\begin{array}{l}\text { Likely } \\
\text { pathogenic }\end{array}$ \\
\hline c. $1947-1 G>C$ & Splicing & - & AML & No & $\begin{array}{l}\text { Likely } \\
\text { pathogenic }\end{array}$ \\
\hline c. $2098-2 A>G$ & Splicing & - & AML & No & Pathogenic \\
\hline \multicolumn{6}{|l|}{ Fragment mutation } \\
\hline $\begin{array}{l}\text { chr16:2112430- } \\
2136922\end{array}$ & - & - & AML & No & Pathogenic \\
\hline
\end{tabular}




\begin{tabular}{|llllll|}
\hline Site & $\begin{array}{l}\text { Mutation } \\
\text { type }\end{array}$ & Protein change & Lesions & $\begin{array}{l}\text { Familial } \\
\text { or not }\end{array}$ & Pathogenicity \\
\hline $\begin{array}{l}\text { chr16:2120398- } \\
2121999\end{array}$ & - & - & AML & No & $\begin{array}{l}\text { Likely } \\
\text { pathogenic }\end{array}$ \\
\hline $\begin{array}{l}\text { c.5027_5068+32del } \\
\text { chr16:2098173- }\end{array}$ & Splicing & p.Leu1676_Asp1690delinsHis & AML & No & $\begin{array}{l}\text { Likely } \\
\text { pathogenic }\end{array}$ \\
\hline $\begin{array}{l}2138668 \\
\text { EX2_16 DEL }\end{array}$ & - & - & $\begin{array}{l}\text { Multiple } \\
\text { renal } \\
\text { cysts }\end{array}$ & Yes & Pathogenic \\
\hline EX22_24 DEL & - & - & AML & No & $\begin{array}{l}\text { Likely } \\
\text { pathogenic }\end{array}$ \\
\hline EX2_42 DEL & - & - & AML & No & $\begin{array}{l}\text { Likely } \\
\text { pathogenic }\end{array}$ \\
\hline
\end{tabular}

The maximum diameters of AMLs in patients who had imaging evaluation in our hospital before any treatment were analyzed according to TSC gene mutations. All the patients presented bilateral involvement. For no patients with TSC1 mutation had pre-treatment imaging records, the AML maximum diameters were compared between patients with TSC2 mutation (TSC2 group) and those with NMI (NMI group). There was no statistically significant difference between two groups ( $11.4 \pm 5.7$ vs. $8.0 \pm 5.6 \mathrm{~cm}, P=0.077)$, and the maximum diameter of $A M L$ in one patient could also be as long as $22.0 \mathrm{~cm}$ in NMI group (Table 5). When considering mutation types, there was also no statistically significant difference among different TSC2 mutation types of nonsense, missense, frameshift, slipping, and fragment deletion ( $P=0.712$ ) (Table 6). No statistically significant difference was found between AML maximus diameters in familial and sporadic patients, either ( $11.4 \pm 5.8 \mathrm{vs} .10 .5 \pm 5.8 \mathrm{~cm}, P=0.663)($ Table 7$)$.

Table 5

Comparison of AML maximum diameters between TSC2 group and NMI group.

\begin{tabular}{|llll|}
\hline & TSC2 group & NMl group & P \\
\hline AML maximum diameter $(\mathrm{cm})$ & $11.4 \pm 5.7$ & $8.0 \pm 5.6$ & 0.077 \\
\hline $\mathrm{N}$, range $(\mathrm{cm})$ & $42,3.0 \sim 26.0$ & $12,2.5 \sim 22.0$ & - \\
\hline
\end{tabular}

Table 5

Comparison of AML maximum diameters between TSC2 group and negative group.

\begin{tabular}{|llll|}
\hline & TSC2 group & NMI group & P \\
\hline AML maximum diameter $(\mathrm{cm})$ & $11.4 \pm 5.7$ & $8.0 \pm 5.6$ & 0.077 \\
\hline $\mathrm{N}$, range $(\mathrm{cm})$ & $42,3.0 \sim 26.0$ & $12,2.5 \sim 22.0$ & - \\
\hline
\end{tabular}


Table 6

Comparison of AML maximum diameters among different TSC2 mutation types.

\begin{tabular}{|lllllll|}
\hline & Nonsense & Missense & Frameshift & Slipping & $\begin{array}{l}\text { Fragment } \\
\text { mutation }\end{array}$ & P \\
\hline $\begin{array}{l}\text { AML maximum diameter } \\
(\mathrm{cm})\end{array}$ & $10.6 \pm 5.1$ & $11.1 \pm 7.1$ & $13.3 \pm 7.3$ & $10.1 \pm 4.4$ & $10.1 \pm 3.6$ & 0.712 \\
\hline $\mathrm{N}$, range $(\mathrm{cm})$ & & & & & & \\
& $16,3.8 \sim$ & $\begin{array}{l}4,3.0 \sim \\
20.2\end{array}$ & $\begin{array}{l}13,3.3 \sim \\
26.6\end{array}$ & $\begin{array}{l}3,5.8 \sim \\
14.6\end{array}$ & $6,5.8 \sim 16.2$ & - \\
\hline
\end{tabular}

Table 7

Comparison of AML maximum diameters between familial and sporadic TSC patients.

\begin{tabular}{|llll|}
\hline & Familial TSC & Sporadic TSC & P \\
\hline AML maximum diameter $(\mathrm{cm})$ & $11.4 \pm 5.8$ & $10.5 \pm 5.9$ & 0.663 \\
\hline N, range $(\mathrm{cm})$ & $11,3.3 \sim 26.6$ & $43,2.5 \sim 22.0$ & \\
\hline
\end{tabular}

\section{Discussion}

TSC is an autosomal dominant genetic disease, which can also occur due to a sporadic germline mutation ${ }^{[12]}$. In 1997, the TSC1 gene on chromosome $9 q 34$ was first discovered ${ }^{[7]}$, while the TSC2 gene on chromosome $16 p 13.3$ was discovered in $1993^{[13]}$. The frequency of TSC2 mutations is reported higher than that in TSC1, and when considering both familial and sporadic conditions, TSC2 mutations are found in about $60 \%$ and TSC1 mutations in about $19 \%$ of TSC patients ${ }^{[14]}$. However, TSC1 or TSC2 mutations cannot be shown by conventional genetic testing in $10 \sim 25 \%$ TSC patients ${ }^{[4]}$. Renal lesions in TSC patients mainly include AMLs and multiple renal cysts, and RCCs are relatively rare. AMLs are the most common renal features in TSC patients. About $80 \%$ of TSC patients develop AMLs, which are significant causes of death. The risk of spontaneous bleeding of AML is related to its volume, and approximately $25 \sim 50 \%$ of AML patients with diameter $>3 \sim 4 \mathrm{~cm}$ will experience hemorrhage ${ }^{[15-16]}$. Except for AMLs, renal cysts are also relatively common TSC renal lesions. PKD1 gene is proximal to TSC2 gene on chromosome 16, which can lead to TSC/PKD contiguous gene syndrome with development of polycystic kidney disease (PKD) ${ }^{[17]}$. The patient who developed bilateral multiple renal cysts in our study also had fragment deletion on TSC2 gene, with his daughter having the same mutation and presenting the same renal lesions. The reasons for TSC patients developing multiple, bilateral RCCs remains unknown, and no other driver mutations have been identified in TSC-associated RCCs ${ }^{[3]}$. There was also a patient with TSC1 gene mutation had bilateral Wilms tumors in our study. Wilms tumor is the most common malignant renal tumor in children. Wilms tumor has a high degree of genetic heterogeneity, and the related genes include WT1 (chromosome 11p13), WTX (chromosome Xq11.1), CTNMB1 (chromosome 3p22.1) and TP53 (chromosome 17p13.1) ${ }^{[18]}$. Spreafico et al reported a girl with TSC2 mutation who developed a unilateral Wilms tumor. However, the girl also was found to have mutations of WT1 and WTX genes ${ }^{[19]}$. According to the existing studies, it is likely that the occurrence of Wilms tumor is coincidental and the conditions of TSC are not associated with an increased risk of Wilms tumor ${ }^{[18]}$. 
TSC2 mutations are usually related to a more severe phenotype than that in TSC1 mutations ${ }^{[20]}$. The ratio of TSC1 mutations in our study is lower than reported, and this may due to more patients with TSC1 mutations had milder phenotypes and patients with TSC2 mutations were more likely to seek treatment. According to previous studies, patients with TSC2 mutations usually have larger AML sizes and higher risk for AML hemorrhage ${ }^{[21]}$. TSC patients with NMI are also reported to have milder phenotypes than patients with TSC2 mutations ${ }^{[22]}$. In our study, we compared AML maximum diameters between patients with TSC2 mutations and NMI, and found that the average of maximum diameters in patients with TSC2 mutations might have a higher trend. However, no statistically significant difference has been found when compared with that in NMI patients. The results may be limited by small samples of patients with NMI. But we also should recognize that the maximum diameter in patients with $\mathrm{NMI}$ can be as long as $22.0 \mathrm{~cm}$.

$21.4 \%$ of TSC patients were classified as NMI, and this ratio is generally consistent with those in previous studies $^{[23]}$. In previous studies, mosaicism and intronic mutations could be identified by NGS in patients who had no mutation identified after conventional molecular diagnostic analysis of TSC1 and TSC2 in the past ${ }^{[5]}$. However, there is still a significant part of patients with NMI in our study with the method of NGS. Nevertheless, it is not possible in our opinion that there is another gene which will lead to typical TSC.

Here we also compare AML sizes among different kinds of mutation types. TSC gene mutations include nonsense mutations, missense mutations, small deletions or insertions, splice site changes and large deletions or rearrangements. Few studies did this work in the past ${ }^{[24]}$, and our results show that there is no direct relationship between mutation types and severity of renal phenotypes. However, further studies, such as those about protein structure and function, should be conducted in the future.

Typically, TSC1 mutations are more likely to be familial than TSC2 mutations ${ }^{[25-26]}$. This phenotypic diversity can be partly explained by the poorer prognosis of patients carrying TSC2 mutations ${ }^{[26]}$. In our study, three of four patients with TSC1 mutations had familial history, while ten of fifty-one patients with TSC2 were familial. Interestingly, two of fifteen patients with $\mathrm{NMI}$ also presented familial disease. This indicates that inherited changes of genes may participate in disease onset, and further studies are needed to find them out.

\section{Conclusions}

The conditions of TSC genetic mutations will affect type and severity of renal lesions. Other focuses such as protein structure and function need to be studied for renal manifestations. Except for patients with TSC1 and TSC2 genetic mutations, patients with $\mathrm{NMI}$ and familial patients are also needed more attention for the pathogenesis of them is still unknown.

\section{Abbreviations}

tuberous sclerosis complex (TSC)

angiomyolipoma (AML)

renal cell carcinoma (RCC)

no mutation identified (NMI) 
next generation sequencing (NGS)

polymerase chain reaction (PCR)

polycystic kidney disease (PKD)

\section{Declarations}

\section{Ethics approval and consent to participate}

The study was approved by the Ethics Committee of Peking Union Medical College Hospital (Beijing, China).

\section{Consent for publication}

Consent for publication was obtained from all the authors.

\section{Availability of data and materials}

The datasets used and/or analyzed during the current study are available from the corresponding author on reasonable request.

\section{Competing interests}

The authors declare that they have no competing interests.

\section{Funding}

The present study was supported by National Natural Science Foundation of China No. 81670611 and No. 81800590.

\section{Authors' contributions}

YZ and HL conceived and designed the study. YC and HF helped to evaluate the feasibility of the study, and guided the implementation. WW, YZ, XW, ZW and GZ performed the data collection. WW conducted data analysis and produced the manuscript.

\section{Acknowledgments}

Not applicable.

\section{References}

[1] Sasongko TH, Ismail NF, Zabidi-Hussin Z. Rapamycin and rapalogs for tuberous sclerosis complex. Cochrane Database Syst Rev. 2016,7:CD011272.

[2] Osborne JP, Fryer A, Webb D. Epidemiology of tuberous sclerosis. Ann N Y Acad Sci. 1991,615:125-7.

[3] Lam HC, Siroky BJ, Henske EP. Renal disease in tuberous sclerosis complex: pathogenesis and therapy. Nat Rev Nephrol. 2018;14(11):704-716. 
[4] Northrup H, Krueger DA, International Tuberous Sclerosis Complex Consensus Group. Tuberous sclerosis complex diagnostic criteria update: recommendations of the 2012 international tuberous sclerosis complex consensus conference. Pediatr Neurol. 2013,49(4):243-54.

[5] Tyburczy ME, Dies KA, Glass J, et al. Mosaic and Intronic Mutations in TSC1/TSC2 Explain the Majority of TSC Patients with No Mutation Identified by Conventional Testing. PLoS Genet. 2015;11(11):e1005637.

[6] Sampson JR, Scahill SJ, Stephenson JB, Mann L, Connor JM. Genetic aspects of tuberous sclerosis in the west of Scotland. J Med Genet. 1989;26(1):28-31.

[7] van Slegtenhorst M, de Hoogt R, Hermans C, et al. Identification of the tuberous sclerosis gene TSC1 on chromosome 9q34. Science. 1997;277(5327):805-808.

[8] Dabora SL, Jozwiak S, Franz DN, et al. Mutational analysis in a cohort of 224 tuberous sclerosis patients indicates increased severity of TSC2, compared with TSC1, disease in multiple organs. Am J Hum Genet. 2001;68(1):64-80.

[9] Sancak O, Nellist M, Goedbloed M, et al. Mutational analysis of the TSC1 and TSC2 genes in a diagnostic setting: genotype--phenotype correlations and comparison of diagnostic DNA techniques in Tuberous Sclerosis Complex. Eur J Hum Genet. 2005;13(6):731-741.

[10] Camposano SE, Greenberg E, Kwiatkowski DJ, Thiele EA. Distinct clinical characteristics of tuberous sclerosis complex patients with no mutation identified. Ann Hum Genet. 2009;73(2):141-146.

[11] Boronat S, Shaaya EA, Doherty CM, Caruso P, Thiele EA. Tuberous sclerosis complex without tubers and subependymal nodules: a phenotype-genotype study. Clin Genet. 2014;86(2):149-154.

[12] Northrup H, Koenig MK, Pearson DA, Au KS. Tuberous Sclerosis Complex. In: Adam MP, Ardinger HH, Pagon RA, et al., eds. GeneReviews®. Seattle (WA): University of Washington, Seattle; 1993.

[13] European Chromosome 16 Tuberous Sclerosis Consortium. Identification and characterization of the tuberous sclerosis gene on chromosome 16. Cell. 1993;75(7):1305-1315.

[14] Kingswood JC, Bruzzi P, Curatolo P, et al. TOSCA - first international registry to address knowledge gaps in the natural history and management of tuberous sclerosis complex. Orphanet J Rare Dis. 2014;9:182.

[15] Dixon BP, Hulbert JC, Bissler JJ. Tuberous sclerosis complex renal disease. Nephron Exp Nephrol. 2011;118(1):e15-e20.

[16] Aydin H, Magi-Galluzzi C, Lane BR, et al. Renal angiomyolipoma: clinicopathologic study of 194 cases with emphasis on the epithelioid histology and tuberous sclerosis association. Am J Surg Pathol. 2009;33(2):289-297.

[17] Bissler JJ, Christopher Kingswood J. Renal manifestation of tuberous sclerosis complex. Am J Med Genet C Semin Med Genet. 2018;178(3):338-347.

[18] Scott RH, Stiller CA, Walker L, Rahman N. Syndromes and constitutional chromosomal abnormalities associated with Wilms tumour. J Med Genet. 2006;43(9):705-715. 
[19] Spreafico F, Notarangelo LD, Schumacher RF, et al. Clinical and molecular description of a Wilms tumor in a patient with tuberous sclerosis complex. Am J Med Genet A. 2011;155A(6):1419-1424.

[20] Peron A, Au KS, Northrup H. Genetics, genomics, and genotype-phenotype correlations of TSC: Insights for clinical practice. Am J Med Genet C Semin Med Genet. 2018;178(3):281-290.

[21] Li S, Zhang Y, Wang Z, et al. Genotype-phenotype correlation of patients with tuberous sclerosis complexassociated renal angiomyolipoma: a descriptive study. Hum Pathol. 2018;82:61-67.

[22] Camposano SE, Greenberg E, Kwiatkowski DJ, Thiele EA. Distinct clinical characteristics of tuberous sclerosis complex patients with no mutation identified. Ann Hum Genet. 2009;73(2):141-146.

[23] Peron A, Vignoli A, Briola F, et al. Deep phenotyping of patients with Tuberous Sclerosis Complex and no mutation identified in TSC1 and TSC2. Eur J Med Genet. 2018;61(7):403-410.

[24] Cai Y, Li H, Zhang Y. Assessment of Tuberous Sclerosis Complex Associated With Renal Lesions by Targeted Next-generation Sequencing in Mainland China. Urology. 2017;101:170.e1-170.e7.

[25] McEneaney LJ, Tee AR. Finding a cure for tuberous sclerosis complex: From genetics through to targeted drug therapies. Adv Genet. 2019;103:91-118.

[26] Jiangyi W, Gang G, Guohai S, Dingwei Y. Germline mutation of TSC1 or TSC2 gene in Chinese patients with bilateral renal angiomyolipomas and mutation spectrum of Chinese TSC patients. Aging (Albany NY). 2020;12(1):756-766. 